\title{
Conditions for and characteristics of nonaqueous micellar solutions and microemulsions with ionic liquids
}

\author{
Oliver Zech ${ }^{a}$ and Werner Kunz ${ }^{* b}$ \\ Received 5th October 2010, Accepted 1st March 2011 \\ DOI: 10.1039/c0sm01103g
}

\begin{abstract}
Research on nonaqueous microemulsions containing ionic liquids as polar and/or apolar phase, respectively, is growing at a fast rate. One key property of ionic liquids that highlights their potential and their diversification compared to water is their wide liquid temperature range. In this emerging-area review article we survey recent developments in the field of nonaqueous micellar solutions and microemulsions containing ionic liquids in general with a strong emphasis on the effect of temperature in particular. Various systems are discussed and compared to their aqueous counterparts.
\end{abstract}

\section{Introduction}

Ionic liquids (ILs) are currently attracting a great deal of research interest in various fields of science and technology. Besides their application in chemical reactions, ${ }^{1,2}$ catalysis ${ }^{3}$ and biocatalysis, ${ }^{4}$ extractions, ${ }^{5}$ electrochemistry, ${ }^{6}$ and preparation of inorganic materials, ${ }^{7}$ they have awaken attention in classical colloid and surface chemistry. ${ }^{8}$ In this context ILs have also been used as media for self-assembly in nonaqueous systems, such as microemulsions or liquid crystalline structures. It may be that much of this work is done simply because ILs are fashionable. In contrast to what is usually published, ILs are not "green" solvents. Their very low

arent a scientist GmbH, Nußbergerstr, 6b, 93053 Regensburg, Germany. ${ }^{b}$ Institute of Physical and Theoretical Chemistry, University of Regensburg, 93040 Regensburg, Germany. E-mail: Werner.kunz@chemie. uni-regensburg.de; Fax: +49 941943 4532; Tel: +499419434044 vapour pressure may even be a disadvantage, when the IL must be separated again from other components in a mixture. Further, more critical studies revealed that most of the ILs are either cytotoxic or poorly biodegradable. Finally, they are often very viscous, much more expensive than conventional solvents and not always sufficiently inert, e.g. against oxidation or hydrolysis. Therefore, we believe that it is important to clearly define the possible advantages of IL containing systems. Why should we make microemulsions with ionic liquids instead of cheap and "green" water?

Before answering this question, we will first discuss the criteria that an IL (or any other solvent) has to fulfill in order to permit structuring of surfactants in it.

\section{Conditions for solvophobic structuring}

Hydrophobic interactions in aqueous media ${ }^{9}$ are essentially one particular example of solvophobic interactions. Although water

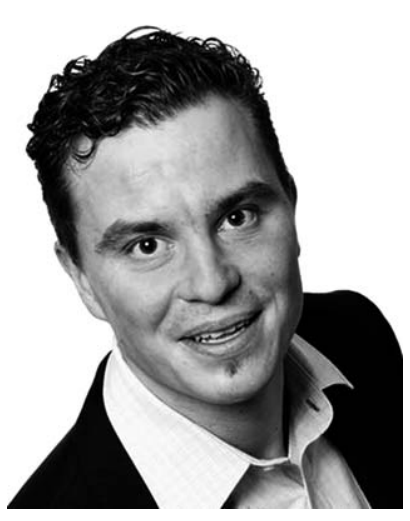

Oliver Zech
Oliver Zech graduated in chemistry at the University of Regensburg, Germany, and obtained his PhD in chemistry in 2010 working on ionic liquids and their application in selfassembled systems. He has completed a postdoc at the MaxPlanck Institute of Colloids and Interfaces, Germany and is currently working at the firm rent a scientist GmbH, Germany. His research interests are in the area of ionic liquids, selfassembly and separation science.

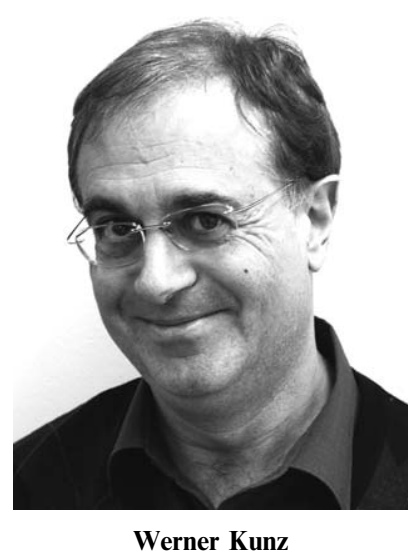

Werner Kunz is the head of the chair of Physical Chemistry II at Regensburg University, Germany. He was a guest professor in France, Belgium and Australia and is a corresponding member of the European Academy of Science and Arts (Paris, London). Among his research interests are solvents, surfactants and ionic solutions. He is also active in formulation chemistry, where he applies academic knowledge to conceive new products, especially for cosmetic, pharmaceutical and household products. 
is a special solvent, it is in many respects not more special than other solvents. For example, peptides show defined folding even in acetonitrile. ${ }^{10}$ Consequently, it is not astonishing that micelles and mesophases are also found in different solvents. That particular hydrogen bonding and the resulting three-dimensional water structure is not a precondition for hydrophobic selfassembly was already found nearly twenty years ago. ${ }^{11,12}$

The idea to formulate nonaqueous self-assembled systems is not new and was first demonstrated in ethylene glycol. ${ }^{13}$ Rico and Lattes proposed fundamental preconditions a solvent should fulfill to promote micelle formation of amphiphiles: ${ }^{14}$ high polarity, high solvating power and the solvent should be highly structured. Micelle formation in various organic solvents, such as hydrazine,$^{15}$ glycerol, formamide, ethylenediamine and 1,3-propanediol has been found. ${ }^{16}$ These organic solvents conform these conditions, for example liquid glycerol exhibits an intermolecular ordering via hydrogen bonding ${ }^{17}$ and can be classified as highly polar $\left(E_{T}^{N}=0.81\right) .{ }^{18}$ The hydrogen bonding or intermolecular ordering of the solvent was supposed to be an indispensable precondition for a solvent to promote aggregation of amphiphiles to micelles, vesicles and bilayers. Although 3-methylsydnone exhibits a very high dielectric constant $\left(\varepsilon\left(40^{\circ} \mathrm{C}\right)=\right.$ $144)^{19}$ and one of the largest dipole moments known for simple molecules $(\mu=7.3 \mathrm{D})^{20}$ it does not promote self-assembly of amphiphiles. ${ }^{21}$ A measure of the cohesive energy density of a liquid, which has widely been used for solvent classification, is the Gordon parameter $G^{22}$ defined as

$$
G=\gamma / V_{m}^{1 / 3}
$$

where $\gamma$ is the air-liquid surface tension and $V_{\mathrm{m}}$ the molar volume. ${ }^{23}$ With decreasing cohesive energy density, the driving force for aggregation decreases accompanied by a rise in the critical micelle concentration (cmc). Evans claimed that liquids with Gordon parameters equal and above $1.3 \mathrm{~J} \mathrm{~m}^{-3}$ tend to promote self-aggregation of amphiphiles, while below this value no self-assembly can be found. ${ }^{23,24}$ Note that classical aprotic solvents fall far below this threshold. 3-Methylsydnone is an exception, because no indication of amphiphilic aggregation could be found even though it has a Gordon value of $1.4 \mathrm{~J} \mathrm{~m}^{-3}{ }^{21}$ The Gordon parameters of several selected organic solvents are given in Table 1 including some representative ILs.

However, whilst the Gordon parameter concept is valuable for solvent classification, it turned out not to be appropriate for

Table 1 Gordon parameters of different solvents at ambient temperature $\left(25^{\circ} \mathrm{C}\right)$ if not elsewise stated

\begin{tabular}{ll}
\hline Solvent & $G / \mathrm{J} \mathrm{m}^{-3}$ \\
\hline Water & 2.821 \\
Hydrazine & 2.121 \\
Glycerol & 1.58 \\
Ethylene glycol & 1.221 \\
Formamide & 1.521 \\
3-Methylsydnone & 1.421 \\
EAN & 1.3 (ref. 21 and 23), $1.1^{a}$ (ref. 26) \\
BAF & 0.726 \\
EAB & 0.626 \\
[bmim][BF $]$ & 0.8 \\
${ }^{a} 27{ }^{\circ} \mathrm{C}$. & \\
\hline
\end{tabular}

a prediction of convenient solvents for solvophobic structuring. Even ILs with very low Gordon parameter values allow for micellar and liquid crystal formation.

In contrast to the Gordon parameter concept, Rico's and Lattes's criteria are quite valuable and help selecting appropriate solvents. Concerning the word "amphiphiles", it should be noted that it is not restricted to classical surfactants. All conceivable micellar and liquid crystal structures imagined for surfactants have also been realised by block copolymers even without any additional solvent.

However, even the Rico-Lattes concept does not comprise all possibilities. It was found that micelles and microemulsions can be made even in supercritical $\mathrm{CO}_{2}$ or in completely unpolar hydrocarbons by using partially fluorinated surfactants. ${ }^{25}$ So it seems that the only necessary (but not sufficient) criterium is the solvophobicity of one part of the surfactant molecule. It is difficult to say more.

\section{Binary IL/surfactant mixtures}

Considering the broad variety of possible solvents for hydrophobic self-assembly, it is not astonishing that ionic liquids have also been tested as media for micelle and liquid crystal formation (note that we do not consider here the case where the IL is used as a surfactant with water as the solvent). In general one can distinguish between self-assembly in protic and aprotic ionic liquids. The most frequently studied aprotic ionic liquids with respect to colloidal systems are based on imidazolium cations combined with anions such as tetrafluoroborate or hexafluorophosphate. In the case of protic ionic liquids (PILs) the most prominent and prevalently studied candidate is ethylammonium nitrate (EAN), which has already been reported in 1914 by Paul Walden. ${ }^{27}$ Micelle formation of cationic and nonionic surfactants in EAN has first been documented in the 1980 s be Evans et al. ${ }^{28,29}$ In addition to micellar structures, liquid crystals of lipids in EAN have been found. ${ }^{30}$ Especially in the past few years there has been a renewed research interest in this field and has been reviewed three times between 2005 and 2008., ${ }^{8,31,32}$ For EAN the cmc of amphiphiles is about ten times higher compared to water ${ }^{28,33,34}$ consistent with a decrease in cohesive energy (cp. Table 1). Greaves et al. demonstrated that many other protic ILs promote self-assembly of amphiphiles as well. ${ }^{26,35}$ They studied the self-assembly behavior of amphiphiles in 22 different protic ILs, fourteen of those were found to assist self-assembly of amphiphiles. ${ }^{35}$ Beside investigations concerning micellar structures in PILs, the formation of liquid crystalline phases of nonionic ${ }^{36-38}$ and ionic surfactants ${ }^{26,39}$ has been documented as well.

A comparison of studies about self-assembly in strongly and weakly structured solvents is of fundamental interest, since it sheds light on the above described concepts. Therefore, the phase behavior of hexadecyltrimethylammonium bromide (CTAB) in water and in PILs will be discussed exemplarily in the following in more detail. Greaves et al. observed for CTAB in PILs two types of phase diagrams, which are illustrated in Fig. 1, middle and right, respectively. ${ }^{26}$ In both types of phase diagrams a solubility temperature exists, below which surfactant crystals coexist with the solvent $(X+S)$, similar to aqueous systems (Fig. 1, left). In the first type of phase diagrams (type a) of CTAB 

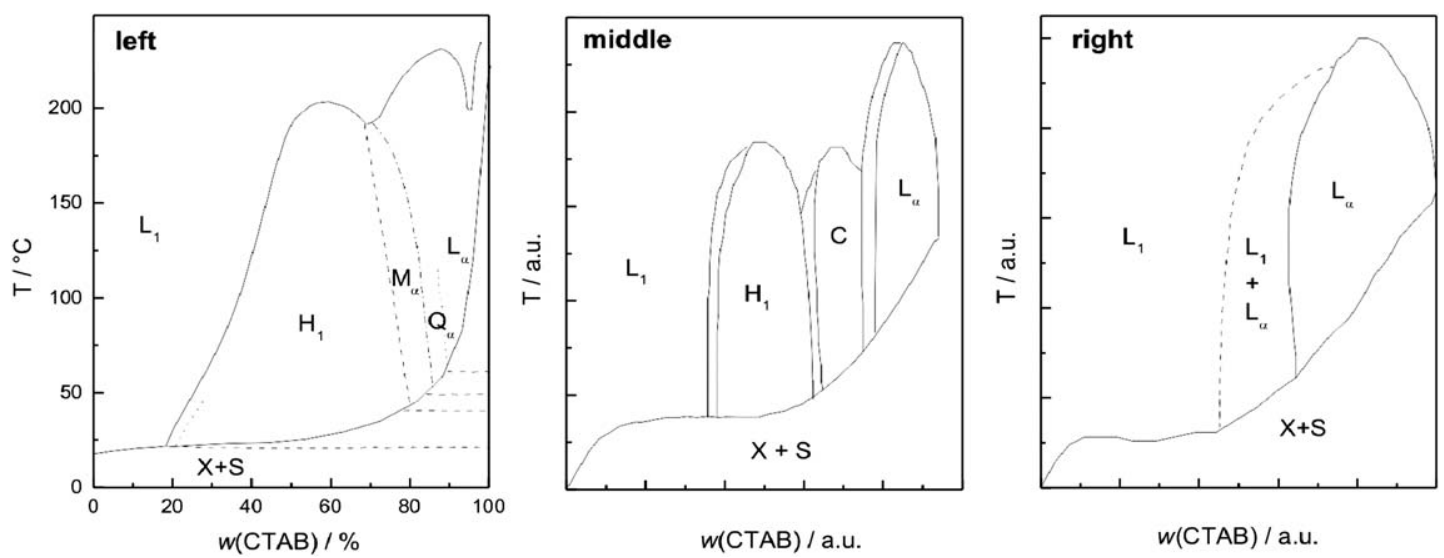

Fig. 1 (left) Phase diagram of the system water/CTAB at different temperatures (redrawn from ref. 41 with permission, copyright American Chemical Society, 1989). Generalized phase diagrams of type a (middle) and type b (right) PIL/CTAB systems (redrawn from ref. 26 with permission, copyright American Chemical Society, 2007).

in PILs (Fig. 1, middle), a transition from a micellar region $\left(\mathrm{L}_{1}\right)$ to a normal hexagonal phase $\left(\mathrm{H}_{1}\right)$ followed by bicontinuous cubic structures $(C)$ and a lamellar phase $\left(\mathrm{L}_{\alpha}\right)$ can be found with increasing $\mathrm{CTAB}$ concentration above the solubility temperature. Compared to the corresponding aqueous phase diagram $^{40-42}$ (Fig. 1, left) the type a phase diagram exhibits many similarities with respect to the type of structures and the order they occur.

By contrast, the type b (Fig. 1, right) phase diagram is significantly different, because only micellar and lamellar structures could be found above the solubility temperature. The type $\mathrm{b}$ phase diagram suggests that the PIL may behave as a cosurfactant and partition into the CTAB aggregates. ${ }^{26}$ Note that in PILs with relatively low $G$ values (e.g. EAB, cp. Table 1) type b phase diagrams can be found, while in PILs with high $G$ values type a phase diagrams prevail.

Self-assembly of amphiphiles in ILs is not restricted to PILs, it has been documented for several aprotic ILs as well. ${ }^{43-45}$ These results demonstrate again that the Gordon parameter concept does not hold for ILs and suggests that the intermolecular ordering of the neat solvent is one key parameter with respect to phase diagrams and phase behavior of amphiphiles in ionic liquids. Concerning the solvent structure in EAN, Evans et al. already claimed in the 1980s three-dimensional hydrogen bonded networks. ${ }^{28,46}$ Atkin and Warr documented small angle neutron scattering (SANS) spectra of selectively deuterated PILs, namely EAN and propylammonium nitrate (PAN) with structure peaks giving evidence of nanosegregation in the bulk. ${ }^{47}$ They attributed these nanoscale heterogeneities to a locally smectic structure. Kennedy and Drummond concluded from electrospray mass spectrometry of several PILs including EAN and PAN the existence of a polydisperse mixture of aggregated ions. ${ }^{48}$ The formation of these aggregates was ascribed to hydrogen bonding between the anions and cations and is hence primarily dependent on the nature of the ions. A structural organization of aprotic ILs has been documented as well. ${ }^{49}$ Neat RTILs consisting of 1-alkyl3-methylimidazolium cations $\left(\left[\mathrm{C}_{n} \mathrm{mim}\right]^{+}\right)$with intermediate length of the alkyl chain $(4 \leq n \leq 10)$ have been studied by means of X-ray diffraction measurements. The existence of a structural organization at the nanometre scale has been found, while the characteristic size of these heterogenicities was linearly dependent on the length $n$ of the alkyl chain..$^{50}$ These findings support the claim that a highly structured solvent is an indispensable condition for self-assembly of amphiphiles in binary solvent/surfactant mixtures. However, this might be misleading. The structuring of 1-butyl-3-methylimidazolium hexafluorophosphate is not very pronounced. Nevertheless it was found that block copolymer systems self-assemble into spherical micelles of the order of $20 \mathrm{~nm}$ in diameter in this IL. ${ }^{51}$ It is probable that the unsolubility of one part of the block copolymer is responsible for micellar formation, and not the structuring of the solvent.

\section{Nonaqueous microemulsions with ILs}

Beyond the extensive amount of research invested into binary IL/ surfactant mixtures important progress has been made in the formulation and characterization of nonaqueous microemulsions. Microemulsions are defined as isotropic, transparent and thermodynamically stable mixtures of at least a hydrophilic, a hydrophobic and an amphiphilic component, while the polar phase is immiscible or at least only partially miscible with the apolar phase. ${ }^{52}$ When using ionic single chain surfactants the addition of a cosurfactant (i.e. $n$-alkanols) that reduces the electrostatic repulsion between the charged surfactant head groups is necessary for the formation of microemulsions. ${ }^{53}$ The growing interest and progress in microemulsions with ionic liquids is reflected in three reviews between 2007 and 2008. ${ }^{8,32,54}$

However, we come back to the question asked in the introduction: what could be the advantage of ILs-based nonaqueous microemulsions? In our opinion, one benefit can be the widely extended temperature range over which microemulsions are stable (possibly from $-50{ }^{\circ} \mathrm{C}$ to $250{ }^{\circ} \mathrm{C}$ or even more). Such systems might find applications e.g. in lubrication under extreme conditions or for controlled nanoparticle synthesis at high temperatures.

As a result we think it is particularly relevant to focus on temperature effects in nonaqueous microemulsions with ILs.

Studies concerning the use of aprotic ILs as water substitute in microemulsions are almost entirely related to imidazolium based substances, where 1-butyl-3-methylimidazolium tetrafluoroborate ([bmim $]\left[\mathrm{BF}_{4}\right]$ ) is the most prominent candidate. Unfortunately, 
recent investigations indicate some limitations especially of aprotic ILs due to their potential cyto- and ecotoxicity. ${ }^{55,56}$ Using $[\mathrm{bmim}]\left[\mathrm{BF}_{4}\right]$ as a polar phase, octylphenol ethoxylate (TX-100) as a surfactant and cyclohexane, ${ }^{57}$ toluene, ${ }^{58} p$-xylene ${ }^{59}$ or benzene ${ }^{60}$ as an oil phase, huge clear and isotropic single phase regions have been documented. Parts of these one phase regions were found to form well-structured microemulsions. Since the nature of the oil did not yield new insights with respect to the type of microstructures occurring, the phase behavior will be exemplarily discussed in the following for the system $[\mathrm{bmim}]\left[\mathrm{BF}_{4}\right] / \mathrm{TX}-100 /$ cyclohexane. Consistent with microstructures known for aqueous microemulsions, oil-in-IL (o/IL) microregions at low amounts of cyclohexane, followed by bicontinuous and IL-in-oil (IL/o) structures with increasing oil content have been identified via conductivity measurements. ${ }^{57}$ Further, freeze fracture transmission electron micrographs (FF-TEM) in the IL/o microregion indicated droplet structures with increasing size when the $R$ value, defined as the molar ratio of $[\mathrm{bmim}]\left[\mathrm{BF}_{4}\right] /$ surfactant, was raised. This swelling behavior was also confirmed by dynamic light scattering (DLS) measurements, although extraordinary large droplet dimensions of the order of $0.1 \mu \mathrm{m}$ at $R=1.5$ have been found and are above the range of conventional microemulsions. By contrast, Eastoe et al. performed SANS experiments on the same system at $55{ }^{\circ} \mathrm{C}$ with comparable $R$ values, ${ }^{61}$ where the data could well be described by a model of ellipsoidal structures with dimensions in the typical range of microemulsions arguing strongly against the radii reported by Gao et al. ${ }^{57}$ The formation of RTIL pools has further been confirmed by time resolved fluorescence spectroscopy using coumarin 153 as probe. ${ }^{62}$ From isothermal titration microcalorimetry measurements $\mathrm{Li}$ et al. concluded substantially stronger nanodroplet interactions showing weakened interdroplet interactions with increasing temperature. ${ }^{63}$ The effect of temperature within $8-55^{\circ} \mathrm{C}$ has further been studied by Gao et al. by means of DLS, freeze-fracture transmission electron microscopy (FF-TEM) and two-dimensional nuclear Overhauser effect (ROESY) experiments. ${ }^{64}$ 2D ROESY spectra indicated structures with $[\mathrm{bmim}]\left[\mathrm{BF}_{4}\right]$ domains, stabilized by a surfactant interfacial film in a continuous oil phase. ${ }^{64}$ Moreover, an increase in droplet size with rising temperature is related to a decrease in interfacial curvature of the surfactant film. Gao et al. supposed that the electrostatic interaction between the $[\mathrm{bmim}]^{+}$cation and the EO units is relatively temperature independent while the solubility of the hydrophobic surfactant chain is temperature sensitive and thus causes the change in interfacial curvature. ${ }^{59}$ However, these microemulsions are relatively temperature insensitive compared to common nonionic surfactant based aqueous microemulsions highlighting fundamental differences between IL and water based microemulsions. The temperature sensitivity of aqueous microemulsions with nonionic surfactants is related to the interaction of water molecules with the EO moieties of the nonionic surfactant. Hence, a temperature change can provoke transitions from w/o to bicontinuous and $\mathrm{o} / \mathrm{w}$ structures. ${ }^{65}$

Besides $[\mathrm{bmim}]\left[\mathrm{BF}_{4}\right]$, different aprotic ILs have been used as water substitutes, ${ }^{66-71}$ but will not be discussed here in detail, since the results do not yield fundamental new physical insights. Cheng et al. investigated promising systems consisting of ethylene glycol (EG) as a polar phase, 1-butyl-3-methylimidazolium hexafluorophosphate $\left(\left[\mathrm{bmim}^{\mathrm{m}}\right]\left[\mathrm{PF}_{6}\right]\right.$ ) as an oil substituent and TX-100 as a surfactant. ${ }^{72}$ Since the vapor pressure of both EG and [bmim] $\left[\mathrm{PF}_{6}\right]$ are very low at ambient temperature, these microemulsions represent an important step towards systems consisting entirely of non-volatile components. Although most studies concerning nonaqueous microemulsions with aprotic ILs deal with nonionic surfactants, ionic surfactants have been used as well. ${ }^{73,74}$

Further to microemulsions with aprotic ILs in nonaqueous microemulsions, PILs have also been utilized as polar phase. Atkin and Warr studied microemulsions composed of nonionic alkyl oligo(ethylene oxide) surfactants $\left(\mathrm{C}_{i} \mathrm{E}_{j}\right)$, alkanes and EAN as polar phase. ${ }^{75}$ For surfactants with increasing amphiphilicity and dodecane as oil phase, fish cuts obtained for an equal ratio of water to oil were found to be very similar to the corresponding aqueous systems. ${ }^{76}$ Moreover, a tricritical point, where the formation of a three phase body occurs, ${ }^{77,78}$ was found for the EAN/ $\mathrm{C}_{i} \mathrm{E}_{j} /$ dodecane systems at amphiphilicities between $\mathrm{C}_{8} \mathrm{E}_{2}$ and $\mathrm{C}_{12} \mathrm{E}_{3}{ }^{75}$ Compared to the aqueous systems ${ }^{78}$ the tricritical point was shifted to higher amphiphilicities. Atkin and Warr further investigated the effect of the alkane alkyl chain length on the phase behavior and phase diagrams. ${ }^{75}$ The phase behavior response to these changes was found to be broadly consistent with aqueous systems, while the effective area of interaction for each EO unit was found to be significantly higher in EAN compared to aqueous systems. Further, SAXS spectra near the point of maximum surfactant efficiency i.e. the minimum amount of surfactant required to solubilize two immiscible solvents exhibited a huge scattering peak, followed by a $q^{-4}$ decay at large $q$ values similar to aqueous systems. These curves could well be described by the Teubner-Strey model. ${ }^{79}$ The authors concluded from the SAXS data that the structuring in EAN microemulsions is higher compared to the aqueous systems. ${ }^{75}$ Zemb et al. interpreted the SAXS data of Atkin and Warr in terms of a dimensionless dilution plot in comparison with the predictions of the models of de Gennes and Taupin, ${ }^{80}$ disordered open connected (DOC) cylinders and DOC lamellar structures. ${ }^{81,82}$ Although none of these models was compatible with the experimental data a simple random microstructure without local order could be excluded and a connected microstructure was found to be plausible. ${ }^{83}$ Moreover, Atkin et al. studied similar systems composed of PAN, $\mathrm{C}_{i} \mathrm{E}_{j}$ and different alkanes. ${ }^{84}$ The phase behavior of these ternary systems was similar to those with water or EAN. Further, SANS contrast variation revealed a cosurfactant like role of the propylammonium cation in these ternary microemulsions.

As already mentioned, one major benefit of ILs in selfassembled systems is the wide liquid range of ILs combined with a low vapor pressure and a high thermal stability. Therefore, we decided to formulate microemulsions that are stable over a wide temperature range. Since nonionic surfactants are more temperature sensitive, the cationic surfactant 1-hexadecyl-3methylimidazoilum chloride $\left(\left[\mathrm{C}_{16} \mathrm{mim}\right][\mathrm{Cl}]\right)$, which is at the same time an ionic liquid, was chosen combined with dodecane as oil phase, decanol as a cosurfactant and EAN or $\left[\mathrm{bmim}^{\mathrm{B}}\right]\left[\mathrm{BF}_{4}\right]$ as a polar phase, respectively. ${ }^{73}$ The area of the one phase region was considerably larger in the case of EAN than for microemulsions with $[\mathrm{bmim}]\left[\mathrm{BF}_{4}\right]$. Furthermore, a significant difference with respect to phase behavior and microemulsions structure has been found. ${ }^{73}$ Since all ingredients show an excellent thermal stability combined with high boiling points and 
decomposition temperatures, respectively, we have recently investigated the thermal stability of the $\left[\mathrm{C}_{16} \mathrm{mim}\right][\mathrm{Cl}]+$ decanol/ EAN/dodecane microemulsions. It could be demonstrated that these microemulsions were stable within a temperature range between 30 and $150{ }^{\circ} \mathrm{C} .{ }^{85,86} \mathrm{~A}$ percolation behavior with increasing amount of EAN could be observed over the whole investigated temperature range by means of conductivity measurements. Interestingly, the percolation threshold was shifted with increasing temperature to lower volume fractions of the dispersed phase, which can be attributed to an increased thermal motion of the nanodomains and thus a higher probability to percolate..$^{85}$ Below this threshold these systems have further been studied by means of temperature dependent SANS experiments, demonstrating clearly a thermal stability of these microemulsions within $30-150{ }^{\circ} \mathrm{C}$. Below the percolation threshold, the data treated by generalized indirect Fourier transformation (GIFT) method ${ }^{87,88}$ suggest a droplet like EAN/o structure over the whole investigated temperature range. The SANS curves for $30^{\circ} \mathrm{C}$ and $150^{\circ} \mathrm{C}$ with the corresponding curves from the GIFT evaluation are illustrated in Fig. 2. The evaluation of the data demonstrated that below the percolation threshold there is no essential variation in shape with increasing EAN content and with increasing temperature. However, these systems represent the first high temperature stable microemulsions at ambient pressure. Moreover, we could demonstrate that biodiesel can act as an oil phase in high temperature microemulsions highlighting a way towards the formulation of biocompatible microemulsions. ${ }^{89}$ These model systems can be extended to other ILs, e.g. $[\mathrm{bmim}]\left[\mathrm{BF}_{4}\right]$ instead of EAN as a polar phase, where a remarkable thermal stability can be achieved as well..$^{90}$

ILs are not only promising candidates for the formulation of high temperature stable colloidal systems, by an appropriate choice of the ingredients also low temperature stable microemulsions can be gained. ${ }^{91}$

Cheng et al. made a major contribution to the formulation of nonaqueous microemulsions with two types of ionic liquids. ${ }^{92}$ For the first time they reported ionic liquid in ionic liquid (IL/IL) structures. For this purpose, the hydrophobic ionic liquid [bmim] $\left[\mathrm{PF}_{6}\right]$ and the hydrophilic protic ionic liquid propylammonium formate (PAF) were used as apolar and polar phases, respectively. Moreover, these microemulsions contained the anionic surfactant sodium bis(2-ethylhexyl) sulfosuccinate

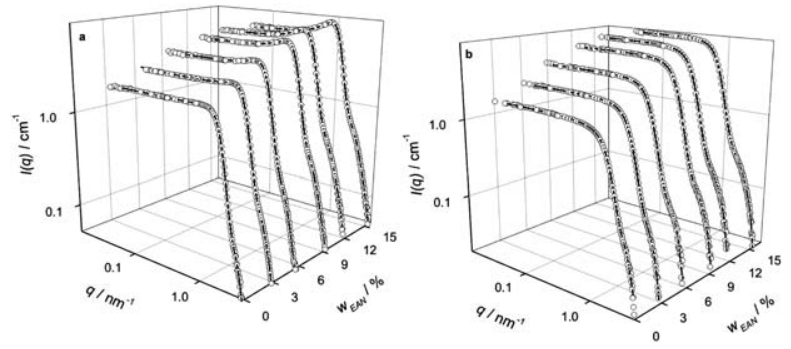

Fig. 2 SANS curves with increasing EAN weight fraction $(0 \%, 3 \%, 6 \%$, $9 \%, 12 \%$, and $16 \%$ ) with a constant weight fraction of surfactant + cosurfactant $(40 \%)$ at $30{ }^{\circ} \mathrm{C}$ (a) and $150{ }^{\circ} \mathrm{C}$ (b), full lines are curves extracted from the GIFT evaluation (reproduced from ref. 86 with permission, copyright Elsevier, 2010).
(AOT). Although the single phase region was extraordinary small, these systems represent an important step towards microemulsions entirely composed of ILs. As far as we know, nobody is currently able to make such microemulsions, in which two immiscible ILs are made compatible by an IL surfactant so that a thermodynamically stable monophasic system is formed.

\section{Replacing traditional oils by ILs}

Although this short review is mainly focused on nonaqueous systems, some attempts to replace the oil phase by an IL in a microemulsion system should be mentioned. Hydrophobic ILs, such as $[\mathrm{bmim}]\left[\mathrm{PF}_{6}\right]$ have been used as apolar phase in quite a few ternary water/IL/surfactant systems ${ }^{49,93-96}$ Gao et al. characterized water/[bmim] $\left[\mathrm{PF}_{6}\right] / \mathrm{TX}-100^{49}$ and water/ $[\mathrm{bmim}]\left[\mathrm{PF}_{6}\right] /$ Tween-20 ${ }^{96}$ systems, respectively. Three kinds of microstructures have been identified, namely micellar $[\mathrm{bmim}]\left[\mathrm{PF}_{6}\right]$ in water, bicontinuous and micellar water in [bmim] $\left[\mathrm{PF}_{6}\right]$ structures. Seth et al. studied in detail the IL/water interaction in these systems. ${ }^{93,94}$ While these studies have been performed at ambient temperature, Anjum et al. investigated the effect of temperature, surfactant concentration and IL mass fraction on the ternary system water/[bmim $]\left[\mathrm{PF}_{6}\right] / \mathrm{TX}-100 .{ }^{95}$ Fish cuts of the system demonstrated a symmetrical shape at intermediate values of the ionic liquid mass fraction $\alpha$, while the fishshaped three phase region was distorted at both high and low values of $\alpha$. It was demonstrated that knowledge gained from classical water/oil/surfactant systems cannot readily be transferred to aqueous microemulsions with ionic liquids as apolar phase. Furthermore, it was shown that ILs with fluorinated ions undergo hydrolysis in the presence of water ${ }^{97}$ which might be a drawback with respect to the long-term stability of aqueous microemulsions with ILs as apolar phase.

\section{Concluding remarks}

In this short review we have summarized recent developments in the formulation of IL based self-assembled systems in general and microemulsions in particular. We tried to show that it is not evident to find criteria that permit prediction of appropriate solvents for microemulsions. The solvent structure may be important, but is neither necessary nor sufficient.

Further, similarities and major differences of nonaqueous microemulsions compared to water have been highlighted, where we distinguished between microemulsions with protic and aprotic ionic liquids. A special emphasis lay on the effect of temperature on these new promising systems. Ionic liquid microemulsions were found to be little sensitive towards temperature. Moreover, by an appropriate choice of the ingredients either high or low temperature stable systems can be generated, which cannot be obtained with conventional aqueous systems. Although the use of these relatively new systems is still scarce so far, ${ }^{71,98-101}$ they may find some applications e.g. as template materials, in nanoparticle synthesis, in water-free organic or inorganic reactions, in separation science, for encapsulation or nanocontainers, as well as in catalysis and biocatalysis. Maybe the remarkable solubilisation capability of some ILs, e.g. towards biopolymers, can be further optimised or exploited by using them in microemulsions. 
However, in future work, it should be clearly indicated what is expected by such systems: is it the extended temperature range? Is it to avoid water and can this not be done by choosing a more classical (and usually cheaper) solvent? Can we use "green" ILs in microemulsions to substitute water? Can we expect enhanced or unconventional solubilisation properties?

In any case, despite significant research on classical microemulsions over the last few decades, their applications are still very restricted, because of the high amount of required surfactant. This might be true also for IL-based non-aqueous microemulsions. Therefore we hope that not hundreds of papers appear dealing with IL-based microemulsions without a clear conception of the usefulness of these studies. The sweeping argument that ILs are "green" should no longer be sufficient.

Finally, we hope that some MD simulations come up dealing with the question of specific intermolecular interactions that are necessary to form defined structures in these systems. To our knowledge there is still not a single simulation on IL-based non-aqueous microemulsions.

\section{References}

1 M. Haumann and A. Riisager, Chem. Rev., 2008, 108, 1474-1497.

2 M. A. P. Martins, C. P. Frizzo, D. N. Moreira, N. Zanatta and H. G. Bonacorso, Chem. Rev., 2008, 108, 2015-2050.

3 V. I. Pârvulescu and C. Hardacre, Chem. Rev., 2007, 107, 2615-2665.

4 F. van Rantwijk and R. A. Sheldon, Chem. Rev., 2007, 107, 27572785.

5 D. Han and K. H. Row, Molecules, 2010, 15, 2405-2426.

6 P. Hapiot and C. Lagrost, Chem. Rev., 2008, 108, 2238-2264.

7 Z. Ma, J. Yu and S. Dai, Adv. Mater., 2010, 22, 261-285.

8 T. L. Greaves and C. J. Drummond, Chem. Soc. Rev., 2008, 37, $1709-1726$.

9 C. Tanford, The Hydrophobic Effect: Formation of Micelles and Biological Membranes, 2nd edn, 1980.

10 K. Huang, C. W. Wu, T. J. Sanborn, J. A. Patch, K. Kirshenbaum, R. N. Zuckermann, A. E. Barron and I. Radhakrishnan, J. Am. Chem. Soc., 2006, 128, 1733-1738.

11 S. Karaborni, N. M. van Os, K. Esselink and P. A. J. Hilbers, Langmuir, 1993, 9, 1175-1178.

12 S. Karaborni, K. Esselink, P. A. J. Hilbers and B. Smit, J. Phys.: Condens. Matter, 1994, 6, A351-A356.

13 A. Ray, J. Am. Chem. Soc., 1969, 91, 6511-6512.

14 A. Lattes and I. Rico, Colloids Surf., 1989, 35, 221-235.

15 M. S. Ramadan, D. F. Evans and R. Lumry, J. Phys. Chem., 1983, 87, 4538-4543.

16 A. Ray, Nature, 1971, 231, 313-315.

17 S. Sarkar and R. N. Joarder, Phys. Lett. A, 1996, 222, 195-198.

18 C. Reichardt, Chem. Rev., 1994, 94, 2319-2358.

19 R. J. Lemire and P. G. Sears, J. Chem. Eng. Data, 1977, 22, 376-379.

20 G. H. Schmid, J. Mol. Struct., 1970, 5, 236-240.

21 A. H. Beesley, D. F. Evans and R. G. Laughlin, J. Phys. Chem., 1988, 92, 791-793.

22 J. E. Gordon, in The Organic Chemistry of Electrolyte Solution, Wiley, New York, 1975, pp. 158-162.

23 D. F. Evans, Langmuir, 1988, 4, 3-12.

24 D. F. Evans and H. Wennerström, in The Colloidal Domain Where Physics, Chemistry, Biology, and Technology Meet, Wiley-VCH, 1998, 2nd edn, pp. 37-42.

25 J. Eastoe, B. M. H. Cazelles, D. C. Steytler, J. D. Holmes, A. R. Pitt, T. J. Wear and R. K. Heenan, Langmuir, 1997, 13, 6980-6984.

26 T. L. Greaves, A. Weerawardena, C. Fong and C. J. Drummond, Langmuir, 2007, 23, 402-404.

27 P. Walden, Izv. Imp. Akad. Nauk, 1914, 8, 405-422.

28 D. F. Evans, A. Yamauchi, R. Roman and E. Z. Casassa, J. Colloid Interface Sci., 1982, 88, 89-96.

29 D. F. Evans, A. Yamauchi, G. J. Wei and V. A. Bloomfield, J. Phys. Chem., 1983, 87, 3537-3541.
30 D. F. Evans, E. W. Kaler and W. J. Benton, J. Phys. Chem., 1983, 87, $533-535$.

31 G. A. Baker and S. Pandey, in ACS Symp. Ser., ed. R. D. Rogers and K. R. Seddon, 2005, vol. 901, pp. 234-243.

32 J. Hao and T. Zemb, Curr. Opin. Colloid Interface Sci., 2007, 12, $129-137$.

33 S. Thomaier and W. Kunz, J. Mol. Liq., 2007, 130, 104-107.

34 S. Bordel Velasco, M. Turmine, D. Di Caprio and P. Letellier, Colloids Surf., A, 2006, 275, 50-54.

35 T. L. Greaves, A. Weerawardena, I. Krodkiewska and C. J. Drummond, J. Phys. Chem. B, 2008, 112, 896-905.

36 T. L. Greaves, A. Weerawardena, C. Fong and C. J. Drummond, J. Phys. Chem. B, 2007, 111, 4082-4088.

37 F. Ma, X. Chen, Y. Zhao, X. Wang, Q. Li, C. Lv and X. Yue, Langmuir, 2010, 26, 7802-7807.

38 M. U. Araos and G. G. Warr, J. Phys. Chem. B, 2005, 109, 1427514277.

39 Y. Zhao, X. Chen and X. Wang, J. Phys. Chem. B, 2009, 113, 2024 2030.

40 T. Wärnheim and A. Jönsson, J. Colloid Interface Sci., 1988, 125, 627-633.

41 X. Auvray, C. Petipas, R. Anthore, I. Rico and A. Lattes, J. Phys. Chem., 1989, 93, 7458-7464.

42 D. Varade, K. Aramaki and C. Stubenrauch, Colloids Surf., A, 2008, 315, 205-209.

43 J. L. Anderson, V. Pino, E. C. Hagberg, V. V. Sheares and D. W. Armstrong, Chem. Commun., 2003, 2444-2445.

44 J. Hao, A. Song, J. Wang, X. Chen, W. Zhuang, F. Shi, F. Zhou and W. Liu, Chem.-Eur. J., 2005, 11, 3936-3940.

45 C. Patrascu, F. Gauffre, F. Nallet, R. Bordes, J. Oberdisse, N. de Lauth-Viguerie and C. Mingotaud, ChemPhysChem, 2006, 7, 99 101.

46 D. F. Evans, S.-H. Chen, G. W. Schriver and E. M. Arnett, J. Am. Chem. Soc., 1981, 103, 481-482.

47 R. Atkin and G. G. Warr, J. Phys. Chem. B, 2008, 112, 4164- 4166.

48 D. F. Kennedy and C. J. Drummond, J. Phys. Chem. B, 2009, 113, $5690-5693$.

49 Y. Gao, S. Han, B. Han, G. Li, D. Shen, Z. Li, J. Du, W. Hou and G. Zhang, Langmuir, 2005, 21, 5681-5684.

50 A. Triolo, O. Russina, H.-J. Bleif and E. Di Cola, J. Phys. Chem. B, 2007, 111, 4641-4644.

51 C. Guerrero-Sanchez, D. Wouters, S. Hoeppener, J.-F. Gohy, H. Thijs, R. Hoogenboom and U. S. Schubert, PMSE Prepr., 2007, 96, 936-937.

52 I. Danielsson and B. Lindman, Colloids Surf., 1981, 3, 391-392.

53 A. M. Bellocq, J. Biais, P. Bothorel, B. Clin, G. Fourche, P. Lalanne, B. Lemaire, B. Lemanceau and D. Roux, Adv. Colloid Interface Sci., 1984, 20, 167-272.

54 Z. Qiu and J. Texter, Curr. Opin. Colloid Interface Sci., 2008, 13, 252-262.

55 B. Jastorff, K. Mölter, P. Behrend, U. Bottin-Weber, J. Filser, A. Heimers, B. Ondruschka, J. Ranke, M. Schaefer, H. Schröder, A. Stark, P. Stepnowski, F. Stock, R. Störmann, S. Stolte, U. Welz-Biermann, S. Ziegert and J. Thöming, Green Chem., 2005, 7, 362-372.

56 S. Stolte, M. Matzke, J. Arning, A. Böschen, W. R. Pitner, U. WelzBiermann and B. Jastorff, Green Chem., 2007, 9, 1170-1179.

57 H. Gao, J. Li, B. Han, W. Chen, J. Zhang, R. Zhang and D. Yan, Phys. Chem. Chem. Phys., 2004, 6, 2914-2916.

58 Y. Gao, S. Wang, L. Zheng, S. Han, X. Zhang, D. Lu, L. Yu, Y. Ji and G. Zhang, J. Colloid Interface Sci., 2006, 301, 612-616.

59 Y. Gao, J. Zhang, H. Xu, X. Zhao, L. Zheng, X. Li and L. Yu, ChemPhysChem, 2006, 7, 1554-1561.

60 Y. Gao, N. Li, L. Zheng, X. Bai, L. Yu, X. Zhao, J. Zhang, M. Zhao and Z. Li, J. Phys. Chem. B, 2007, 111, 2506-2513.

61 J. Eastoe, S. Gold, S. E. Rogers, A. Paul, T. Welton, R. K. Heenan and I. Grillo, J. Am. Chem. Soc., 2005, 127, 7302-7303.

62 D. Chakrabarty, D. Seth, A. Chakraborty and N. Sarkar, J. Phys. Chem. B, 2005, 109, 5753-5758.

63 N. Li, S. Zhang, L. Zheng, Y. A. Gao and L. Yu, Langmuir, 2008, 24, 2973-2976.

64 Y. Gao, N. Li, L. Hilfert, S. Zhang, L. Zheng and L. Yu, Langmuir, $2009,25,1360-1365$.

65 K. Wormuth, O. Lade, M. Lade and R. Schomacker, in Handbook of Applied Surface and Colloid Chemistry, 2002, vol. 2, pp. 55-77. 
66 J. Li, J. Zhang, H. Gao, B. Han and L. Gao, Colloid Polym. Sci., 2005, 283, 1371-1375.

67 A. Adhikari, K. Sahu, S. Dey, S. Ghosh, U. Mandal and K. Bhattacharyya, J. Phys. Chem. B, 2007, 111, 12809-12816.

68 A. Adhikari, D. K. Das, D. K. Sasmal and K. Bhattacharyya, $J$. Phys. Chem. A, 2009, 113, 3737-3743.

69 Y. Zheng and W. Eli, J. Dispersion Sci. Technol., 2009, 30, 698-703.

70 Y. Zheng, W. Eli and G. Li, Colloid Polym. Sci., 2009, 287, 871876.

71 F. Gayet, C. El Kalamouni, P. Lavedan, J.-D. Marty, A. Brûlet and N. Lauth-de Viguerie, Langmuir, 2009, 25, 9741-9750.

72 S. Cheng, X. Fu, J. Liu, J. Zhang, Z. Zhang, Y. Wei and B. Han, Colloids Surf., A, 2007, 302, 211-215.

73 O. Zech, S. Thomaier, P. Bauduin, T. Rück, D. Touraud and W. Kunz, J. Phys. Chem. B, 2009, 113, 465-473.

74 C. Rabe and J. Koetz, Colloids Surf., A, 2010, 354, 261-267.

75 R. Atkin and G. G. Warr, J. Phys. Chem. B, 2007, 111, 93099316.

76 M. Kahlweit, R. Strey and G. Busse, Phys. Rev. E: Stat. Phys., Plasmas, Fluids, Relat. Interdiscip. Top, 1993, 47, 4197-4209.

77 M. Kahlweit, R. Strey, P. Firman and D. Haase, Langmuir, 1985, 1, 281-288.

78 M. Kahlweit, R. Strey and P. Firman, J. Phys. Chem., 1986, 90, 671677.

79 M. Teubner and R. Strey, J. Chem. Phys., 1987, 87, 3195-3200.

80 P. G. De Gennes and C. Taupin, J. Phys. Chem., 1982, 86, 2294 2304.

81 T. N. Zemb, I. S. Barnes, P. J. Derian and B. W. Ninham, Prog. Colloid Polym. Sci., 1990, 81, 20-29.

82 T. N. Zemb, Colloids Surf., A, 1997, 129-130, 435-454.

83 T. N. Zemb, C. R. Chim., 2009, 12, 218-224.

84 R. Atkin, S. M. C. Bobillier and G. G. Warr, J. Phys. Chem. B, 2009 , 114, 1350-1360.
85 O. Zech, S. Thomaier, A. Kolodziejski, D. Touraud, I. Grillo and W. Kunz, Chem.-Eur. J., 2010, 16, 783-786.

86 O. Zech, S. Thomaier, A. Kolodziejski, D. Touraud, I. Grillo and W. Kunz, J. Colloid Interface Sci., 2010, 347, 227-232.

87 J. Brunner-Popela and O. Glatter, J. Appl. Crystallogr., 1997, 30, $431-442$.

88 B. Weyerich, J. Brunner-Popela and O. Glatter, J. Appl. Crystallogr., 1999, 32, 197-209.

89 O. Zech, P. Bauduin, P. Palatzky, D. Touraud and W. Kunz, Energy Environ. Sci., 2010, 3, 846-851.

90 O. Zech, Dissertation, Regensburg, 2010.

91 A. Harrar, O. Zech, R. Hartl, P. Bauduin, T. Zemb and W. Kunz, Langmuir, 2011, 27, 1635-1642.

92 S. Cheng, J. Zhang, Z. Zhang and B. Han, Chem. Commun., 2007, 2497-2499.

93 D. Seth, A. Chakraborty, P. Setua and N. Sarkar, Langmuir, 2006, 22, 7768-7775.

94 D. Seth, A. Chakraborty, P. Setua and N. Sarkar, J. Chem. Phys., 2007, 126, 224511-224512.

95 N. Anjum, M.-A. Guedeau-Boudeville, C. Stubenrauch and A. Mourchid, J. Phys. Chem. B, 2009, 113, 239-244.

96 Y. A. Gao, N. Li, L. Zheng, X. Zhao, S. Zhang, B. Han, W. Hou and G. Li, Green Chem., 2006, 8, 43-49.

97 R. P. Swatloski, J. D. Holbrey and R. D. Rogers, Green Chem., 2003, 5, 361-363.

98 M. Zhao, L. Zheng, X. Bai, N. Li and L. Yu, Colloids Surf., A, 2009, 346, 229-236.

99 F. Yan, S. Yu, X. Zhang, L. Qiu, F. Chu, J. You and J. Lu, Chem. Mater., 2009, 21, 1480-1484.

100 Z. Chen, F. Yan, L. Qiu, J. Lu, Y. Zhou, J. Chen, Y. Tang and J. Texter, Langmuir, 2010, 26, 3803-3806.

101 M. Moniruzzaman, Y. Tahara, M. Tamura, N. Kamiya and M. Goto, Chem. Commun., 2010, 46, 1452-1454. 